\title{
Calculating the Financial Health Economic Impact of Weight Loss in Obese Populations
}

\author{
Article by Ana Cristina Diniz Silva \\ MD, MSc Postgraduate student in Obesity and Weight Management, University of \\ South Wales (UK), Brazil \\ Email: anacristina@sernobre.com.br
}

\begin{abstract}
Health promotion programs have been constantly developed by the Health Surveillance Agencies of many countries aiming at tackling obesity. U.S. data revealed impressive obesityrelated costs of $\$ 117$ billion in 2000 - \$61 billion for direct medical costs and \$56 billion for indirect costs, i.e., those related to the impact of the disease on the country's economy. In the UK, economic projections revealed that indirect costs might have reached $£ 27$ billion by 2015. The majority of the educational and preventive actions target lifestyle changes, childhood obesity and diabetes. More than making the population aware of the benefits of healthier habits and their potential savings, stakeholders and funders are looking forward to better assessing the economic impact of health education programs, which can be quantified by different methods such as the time value of money analyses, shadow pricing, and the costbenefit and cost-effectiveness indexes. In the specific case of obesity as a risk factor for cardio-metabolic diseases, estimates obtained from different analysis reveal that great amounts of money - as high as 11.2 billion dollars - can be saved by delaying type 2 diabetes onset in 6 years, in a hypothetical population of 2 million obese adults who have effectively lost weight. Furthermore, in agreement with the ancient philosopher Virgil, who quoted "the greatest wealth is health", by living longer and healthier, people may produce more and improve individual and familiar financial lives, thus contributing economically to their communities and countries. The aim of this paper is to briefly report how to assess and calculate the financial impact of public health programs to tackle obesity.
\end{abstract}

Keywords: obesity, public health, weight loss, economy, cost-benefit, cost-effectiveness

\section{Introduction}

Over the years, several studies have estimated health-care expenditures attributable to obesity. Such estimates show great variations, mostly because many of them do not consider the "extra" costs of comorbidities that often occur during the gained years of life ${ }^{1}$. One of these studies, having taken into account those extra-costs, estimated the lifetime obesity related costs (20-85 years of age) in $4.32 \%$. In other words, "if obesity were prevented (at no charge) before 20 years of age and the cohort remained non-obese throughout life, then, in the subsequent 65 years, direct healthcare costs would be reduced by $4.32 \%$ "2 .

U.S. data revealed impressive obesity-related costs of $\$ 117$ billion in 2000 - \$61 billion for direct medical costs and $\$ 56$ billion for indirect costs, i.e., those related to the impact of the disease on the country's economy, e.g., loss of productivity ${ }^{3}$. The National Health Service (NHS) estimated a great increase of the costs for treating obesity and comorbidities in England, ranging from $£ 479.3$ million in 1998 to $£ 4.2$ billion in 2007. Indirect costs have been estimated between $£ 2.6$ billion and $£ 15.8$ billion. Economic projections revealed that indirect costs might have reached $£ 27$ billion by $2015^{4}$.

Health promotion programs have been constantly developed by the Health Agencies of many countries. In the obesity field specifically, such programs target childhood obesity, diabetes, implementation of physical activity facilities and dissemination of healthy eating habits. Impacts of public health actions are often evaluated by positive changes in the population's lifestyle and, more objectively, by the reduction in weight and body mass index (BMI). Additionally, stakeholders and funders are looking forward to analyzing the economic 
impact of health education programs, which can be quantified by different methods ${ }^{5}$. The aim of this paper is to briefly report how to assess and calculate the financial impact of public health programs to tackle obesity.

\section{Methods}

The assessment of the economic impact of health education programs can be quantified by different methods, such as the time value of money analyses, shadow pricing, and the costbenefit and cost-effectiveness indexes, which are described below assuming the specific case of obesity and weight control.

\section{Results}

The first way to assess the economic impact of an educational program is through a survey among the participants. An example is the interdisciplinary program called Small Steps to Health and Wealth ${ }^{\mathrm{TM}}$ (SSHW): according to it, making positive lifestyle changes will lead to improvement in both health and personal finances. Periodically, participants complete evaluation surveys that focus on their health, finances, and the relationship between them ${ }^{6}$. This method of qualitative analysis is useful as a complement of the more objective quantitative data, described below.

The motivation to make positive lifestyle changes may arise from the identification of known beneficial practices and the potential savings that these changes can bring. Some examples of behavioral changes and their related savings are shown in the Table 17. If we assume that the enlisted lifestyle changes can be fully implemented in a hypothetical obese population of 2 million adults, a simple calculation will reveal annual savings of about 5.7 billion dollars.

Table 1: The Financial Impact of Improved Health Behaviors Worksheet (adapted) ${ }^{7}$.

\begin{tabular}{|l|c|c|}
\hline \multicolumn{1}{|c|}{ Improved Health/Nutrition Practice } & $\begin{array}{c}\text { Weekly } \\
\text { Savings }\end{array}$ & $\begin{array}{c}\text { Annual } \\
\text { Savings }\end{array}$ \\
\hline $\begin{array}{l}\text { Saving US\$3 a day currently spent on junk food, fast food, } \\
\text { or alcohol }\end{array}$ & US\$21 & US\$1,092 \\
\hline Getting two meals from one by eating smaller servings & US\$ 9 & US\$ 468 \\
\hline $\begin{array}{l}\text { Substituting pasta, beans, soups, etc. for meat 2-3 times } \\
\text { per week }\end{array}$ & US\$15 & US\$ 780 \\
\hline $\begin{array}{l}\text { Reduce the number of meals eaten away from home by } \\
\text { two }\end{array}$ & US\$10 & US\$ 520 \\
\hline
\end{tabular}

Another way to determine the economic impact of a program is the "time value of money analyses". Through this method, we can calculate how much can be saved if a disease onset is delayed, type 2 diabetes (DM2) for example, thus measuring the financial impact and the effectiveness of a determined program ${ }^{5}$. We can use again the example of a hypothetical population of 2 million obese adults, who have effectively lost weight, to have such calculation done.

Health care costs for a diabetic patient are estimated in US\$13,243 annually; the same costs for a non-diabetic person are US $\$ 2,560$, a difference of $\$ 10,683^{3}$. Consider the average age of DM2 onset in the assumed obese population is 40 years, with a $5 \%$ discount rate. Thinking in a realistic rate in which $10 \%$ of the 2 million participants $(200,000)$ are able to have a delayed onset of diabetes after losing weight, pushing back the average age from 40 to 46, and avoiding the $\$ 10,683$ annual costs, the economic benefit could be calculated:

- Annuity value $=6$ years of delay $* 5 \%$ discount rate $=5.2421$

- $\quad$ Per person $=\$ 10,683 \times 5.2421=\$ 56,001$

- $\quad$ For the population $=\$ 56,001 \times 200,000=\$ 11.2$ billion!

"Shadow pricing" technique, on the other hand, is based on simple extrapolations from trustable published data that demonstrate the money savings of successful health programs ${ }^{5}$. 
For instance, the American CDC revealed that annual medical costs of overweight/obese people who lose $10 \%$ of their weight could be reduced by $\$ 2,200-\$ 5,300$ by decreasing costs associated with diabetes, hypertension, dyslipidemia and cardiovascular diseases ${ }^{3}$. Using simple math, considering the same 2 million obese populations with an average weight of $80 \mathrm{~kg}$, a sustained weight loss of $10 \%$, i.e., $8 \mathrm{~kg}$, means saving a range from 4.4 to 10.6 billion dollars yearly.

Cost-benefit analysis is also an effective method to assess the economic impacts of health interventions. Costs refer to the required resources for planning, implementing and concluding a program, e.g., staff salaries, trips, publications, equipment, phone calls, supplies, etc. They are determined by placing a dollar value on the currency. On the other side, benefits are the positive outcomes originated from the health intervention, such as money saving and debts reduction ${ }^{8}$.

A robust meta-analysis on the workplace wellness programs and their related costs and savings demonstrated annual average savings of \$358 per employee as the result of health improvement, while the firms spent \$144 per employee per year. Across the 15 trials that were reviewed, the authors estimated an average return of 3.27 from the initial investment, i.e., for every dollar spent, $\$ 3.27$ was saved. In addition, for every dollar spent, costs related to absenteeism fell by about $\$ 2.73$. More than $90 \%$ of the wellness interventions analyzed in this meta-analysis took place in large firms with more than 1,000 employees. One-fourth of the programs involved more than 10,000 workers $^{9}$. Similar results had been previously reported from Australian data of weight loss programs. The authors revealed an average costbenefit of $\$ 428$ per enrolment, and a benefit-cost ratio of $3.2^{10}$.

Worksite interventions target people from 18 to 65 years old. Workers influenced by such programs may represent as much as $15.7 \%$ of a country's population ${ }^{11}$. Brazilian population is estimated in about 205.5 million people12 - 15.7\% representing 32.26 million workers. In Brazil, obesity prevalence among adults is estimated in $15 \%(\mathrm{BMI}>30 \mathrm{~kg} / \mathrm{m} 2)^{13}$, meaning that among those aged 18-65 years who are the target population of work place programs for weight loss, 4.8 million are obese. According to Cecchini et al.11, these worksite campaigns spend about US\$0.82 per head in Brazil, meaning a total cost of 26.5 million dollars yearly to cover 32.26 million people. Considering a benefit-cost ratio of 3.2, about $\$ 84.8$ million should be annually saved ${ }^{9,10}$. The same calculations may be applied for other health programs to tackle obesity, such as mass media campaigns, fiscal measures, physician counseling, food labeling, advertising regulation and, targeting children, school interventions, as shown in Table 2. Summing up all these efforts and investments would result in approximately 380 million dollars savings in Brazil per year, involving the entire obese population, i.e., 30.8 million people $\mathrm{e}^{11,13}$.

Table 2: Summary of coverage and costs of selected preventive interventions for weight loss in Brazil (adapted from Cecchini et al., 2010).

\begin{tabular}{|l|l|l|l|l|l|l|l|}
\hline Target & $\begin{array}{l}\text { School } \\
\text { actions }\end{array}$ & $\begin{array}{l}\text { Worksite } \\
\text { actions }\end{array}$ & $\begin{array}{l}\text { Mass } \\
\text { media } \\
\text { campaigns }\end{array}$ & $\begin{array}{l}\text { Fiscal } \\
\text { measures }\end{array}$ & $\begin{array}{l}\text { Physician } \\
\text { counseling }\end{array}$ & $\begin{array}{l}\text { Food } \\
\text { advertising } \\
\text { regulation }\end{array}$ & $\begin{array}{l}\text { Food } \\
\text { labeling }\end{array}$ \\
\hline Age & $8-9$ & $18-65$ & $>18$ & $>0$ & $22-65$ & $2-18$ & $>0$ \\
\hline $\begin{array}{l}\text { \% of the } \\
\text { population }\end{array}$ & $1.7-4.2$ & $3.4-15.7$ & $61.1-80.4$ & 100 & $1.1-14.7$ & $19.3-36.5$ & 100 \\
\hline $\begin{array}{l}\text { Cost per } \\
\text { head* }\end{array}$ & 0.82 & 0.82 & 0.27 & 0.01 & 1.71 & 0.04 & 0.15 \\
\hline
\end{tabular}

* 2005 US\$

Health interventions contribute to a later onset of chronic diseases, instead of preventing their occurrence. Such beneficial effect on morbidity can be assessed by calculating the averted disability-adjusted life-years (DALYs). The cost-effectiveness ratios (CE) of a determined program are calculated in dollars per DALY averted, thus representing the money 
saved from each additional year of healthy life, in comparison with a no-prevention or treatment-only scenario ${ }^{11}$.

Table 3 shows the CE of some weight loss programs in Brazil. Taking as example worksite interventions, the DALY averted per million population is 1,187 in the medium-term (20 years). The estimated CE of this intervention is 8,270, which means that for an obese population of 4.8 million workers, about 47 million dollars might be saved if weight is effectively lost in that period. When considering other weight loss interventions (table 3), cost savings could reach 1.5 billion dollars if the 30.8 million obese Brazilian populations is fully covered, over a period of 20 years ${ }^{11}$.

Table 3: E-activeness and cost- activeness of heath interventions after 20 years in Brazil. DALYs = disability-adjusted life-years saved per million population. $\mathrm{CE}=$ cost-e-activeness ratios, expressed in US\$ per DALY averted (adapted from Cecchini et al., 2010).

\begin{tabular}{|l|l|l|l|l|}
\hline Weight loss programs & DALYs & CE (US\$) & $\begin{array}{l}\text { Total savings (US\$ per million } \\
\text { population) }\end{array}$ \\
\hline Worksite interventions & 1,187 & 8,270 & 9.8 million \\
\hline Mass media campaigns & 627 & 5,074 & 3.2 million & \\
\hline Physician counseling & 2,805 & 8,503 & 23.85 million \\
\hline $\begin{array}{l}\text { School-based } \\
\text { interventions }\end{array}$ & 4 & $*$ & $>4$ million \\
\hline Food labeling & 1,030 & 9,962 & 10.26 million \\
\hline
\end{tabular}

\section{Discussion}

Here a comparison becomes necessary between the investments and preventive actions to tackle obesity in a developed and in a developing country, such as England and Brazil for instance. England's population is estimated in 53.8 million people14 - 15.7\% representing 8.44 million workers. In this country, obesity prevalence among adults is $25.6 \%$, i.e., among those aged 18-65 years who are the target population of work place programs for weight loss, 2.16 million are obese15. In that country, these worksite campaigns spend about US\$5.48 per head (versus \$0.82 in Brazil), meaning a total cost of 46.2 million dollars yearly to cover 8.44 million people ${ }^{11}$. Considering a benefit-cost ratio of 3.2, about $\$ 148$ million should be annually saved ${ }^{9,10}$. Summing up all health programs and investments that target the entire obese population of 13.8 million people would result in costs of approximately $\$ 287.5$ million (versus $\$ 118.7$ million in Brazil). The assumed benefit-cost ratio of 3.2 would lead to $\$ 920$ million savings in England per year, in comparison to $\$ 380$ million in Brazil, i.e., 2.4 times higher $^{11,15}$.

Also in England, through worksite interventions, the DALY averted per million populations are 1,725 over a 20-year period. The estimated CE of this intervention is 45,630, which means that for an obese population of 2 million workers, about 157 million dollars might be saved if weight is effectively lost in that period. When considering other weight loss interventions, cost savings could reach 3.8 billion dollars within 20 years, if the obese English population is fully covered (2.5 times the Brazilian estimates) ${ }^{11}$.

Comparing public health data in England and Brazil, it is not difficult to observe the outstanding differences between the investments aiming at weight loss in these countries, even whether considering that England's obese population is less than half of Brazilian's. Not less important to be pointed out is that, the higher the investments in education health programs, the higher the return, in terms of both cost-benefit and cost-effectiveness.

\section{Conclusions}

Health programs supported by the government or large firms are highly expected to bring sufficient public benefits to make them worthy of reducing medium- and long-term expenditures in health care, like expensive medications, hospitalizations, surgeries, etc. In 
contrast with financial management programs that rely on economic indicators, the impacts and outcomes of health education interventions are often calculated indirectly. In the specific case of obesity, which is a well-established risk factor of serious diseases like diabetes and cardiovascular diseases, estimates obtained from different methods reveal that great amounts of money - as high as 11.2 billion dollars - may be saved by delaying 2DM onset in 6 years, in a hypothetical population of 2 million obese adults who lost weight.

More than the public and entrepreneurial investments on preventive actions in health, healthier lifestyle choices elevate the odds of living longer and better. Healthy people who live longer produce more as they have more time to increase their savings. In this line of thought, the economy of a country or a community may improve due to this secondary effect of health programs in individual and familiar financial lives.

\section{References}

[1.] Allison D, Zannolli R, Narayan K. The direct health care costs of obesity in the United States. Am J Public Health. 1999;89(8):1194-1199. PMC1508703

[2.] Arbex AK, Rocha DR, Aizenberg M, \& Ciruzzi MS. (2014). Obesity epidemic in Brazil and Argentina: a public health concern. J Health Popul Nutr. 2014;32(2):327-334. PMC4216968

[3.] Baicker K, Cutler D, Song Z. Workplace Wellness Programs Can Generate Savings. Health Affairs. 2010;29(2):304-311. DOI: 10.1377/hlthaff.2009.0626

[4.] Cecchini M, Sassi F, Lauer J, Lee Y, Guajardo-Barron V, Chisholm D. Tackling of unhealthy diets, physical inactivity, and obesity: health effects and cost-effectiveness. The Lancet. 2010;376(9754):1775-1784. DOI: http://dx.doi.org/10.1016/S0140-6736(10)61514-0

[5.] Centers for Disease Control and Prevention (CDC). Preventing obesity and chronic diseases through good nutrition and physical activity. Atlanta, Georgia: US Department of Health and Human Services, Centers for Disease Control and Prevention. 2003;14(18):14.

[6.] Ibge.gov.br. IBGE | Projeção da população [Internet]. 2016 [cited 21 February 2016]. Available from: http://www.ibge.gov.br/apps/populacao/projecao/

[7.] Murphy C \& Yates J. Economic comparison of weight loss programmes versus drug treatment for the management of obesity. Asia Pac J Clin Nutr. 2005;14(Suppl):S97-S105.

[8.] Noo.org.uk. The economic burden of obesity. Home :: Public Health England Obesity Knowledge and Intelligence team [Internet]. 2010 [cited 10 February 2016]. Available from: http://www.noo.org.uk

[9.] Noo.org.uk. UK and Ireland prevalence and trends :: Public Health England Obesity Knowledge and Intelligence team [Internet]. 2014 [cited 10 February 2016]. Available from: https://www.noo.org.uk/NOO_about_obesity/adult_obesity/UK_prevalence_and_trends

[10.] Njaes.rutgers.edu. The Financial Impact of Improved Health Behaviors [Internet]. [cited 10 February 2016]. Available from: https://njaes.rutgers.edu/healthfinance/health-behaviors.asp

[11.] O’Neill, B. Calculating the Economic Impact of Health Education Programs: Five Tools for Extension Educators [Internet]. Joe.org. 2008 [cited 10 February 2016]. Available from: http://www.joe.org/joe/2008february/tt4.php

[12.] O'Neill, B. Health and wealth connections: Implications for financial planners. JPF. 2005;4(2):2738.

[13.] O’Neill B, \& Richardson J. Cost-Benefit Impact Statements: A Tool For Extension Accountability [Internet]. Joe.org. 1999 [cited 10 February 2016]. Available from: http://www.joe.org/joe/1999august/tt3.php

[14.] Ons.gov.uk. UK Statistics - Population and migration - ONS [Internet]. 2014 [cited 10 February 2016]. Available from: http://www.ons.gov.uk/ons/guide-method/compendiums/compendium-of-ukstatistics/population-and-migration/index.html

[15.] van Baal P, Polder J, de Wit G, Hoogenveen R, Feenstra T, Boshuizen H et al. Lifetime Medical Costs of Obesity: Prevention No Cure for Increasing Health Expenditure. PLoS Med. 2008;5(2):e29. DOI: 10.1371/journal.pmed.0050029 